\title{
The use of explosive welding for manufacturing of bimetallic pipe billets with internal layer made of heat-resistant nickel-cobalt alloy EK102
}

\author{
A.Yu. Malakhov ${ }^{\dagger}$ I.V. Saikov, O.L. Pervukhina \\ †sir.malahov2009@yandex.ru
}

Institute of Structural Macrokinetics and Materials Science RAS, 8 Academician Osip'yan St.,132432 Chernogolovka, Russia

The features of bonding between layers in two-layer tubular billets have been studied after explosive welding. In doing so, the steel OHN3M and the nickel-cobalt alloy EK102 (the both are the Russian abbreviations) were used as the layer materials. The EK102 alloy contains such high-melting metals as tungsten, cobalt and chromium and therefore the bonding of this alloy with others is very difficult irrespective of welding technique. One of the factors, which makes difficult obtaining high-quality bimetallic products out of these components by explosive welding is the presence of a refractory film on the alloy surfaces, which hinders the process of self-purification and activation of surfaces during explosive welding. The scheme of coating of the internal cylindrical surface of a tubular billet made of steel OHN3M by the alloy EK102 was developed. Explosive welding was carried out using the scheme with a synchronous initiation of opposite charges. This scheme was chosen as an alternative to welding of cylindrical items in a matrix. As a result of experiments, bimetallic pipe samples without any visible damages in the inner and outer layers were obtained. Ultrasonic testing showed $100 \%$ bonded layers along the length of the pipe billets. Further studies were carried out for the circular specimens, which were cut from the pipe billet. The microstructure near the welding joint was investigated. Radial compression tests of circular specimens were performed. The maximum load was 10 tons. During inspection of the bimetal welded joint the layering was not detected. Thus, the processing regimes of explosive welding allowed us to create the prerequisites for removing the oxide films from the high-melting alloys during the welding process and provided high adhesion strength of the layers without formation of continuous melted interlayers.

Keywords: explosive welding, heat-resistant alloy, casting defects, bimatallic pipe billet.

\section{Получение сваркой взрывом биметаллических трубных заготовок с внутренним жаропрочным слоем из никель- кобальтового сплава ЭК102}

\author{
Малахов А.Ю. ${ }^{\dagger}$, Сайков И.В., Первухина О.Л. \\ ФГБУН Институт структурной макрокинетики и проблем материаловедения РАН, \\ ул. Академика Осипьяна, д.8, 132432, г. Черноголовка, Россия
}

\begin{abstract}
Исследованы особенности получения соединения сваркой взрывом в двухслойных трубных заготовках с сочетанием слоев сталь ОХНЗМ и жаропрочный никель-кобальтовый сплав ЭК102. В связи с тем, что в составе сплава ЭК102 присутствуют такие тугоплавкие металлы, как вольфрам, кобальт, и хром соединение всеми видами сварки данного сплава с другими материалами затруднено. Одним их факторов, затрудняющих качественное получение сваркой взрывом биметаллического изделия из указанных компонентов, является наличие тугоплавкой пленки на поверхности жаропрочного сплава, которая препятствует процессу самоочищения и активации поверхностей в процессе сварки взрывом. Разработана схема плакирования сплавом ЭК102 внутренней части цилиндрической поверхности из стали ОХНЗМ. Сварка взрывом исходных материалов осуществлялась по схеме с синхронным инициированием противозарядов. Данная схема была выбрана как альтернатива сварке цилиндрических изделий в матрице. В результате экспериментов были получены биметаллические трубные образцы без видимых повреждений внутреннего и наружного слоя. Ультразвуковой контроль показал 100\% сплошность сцепления слоев по всей длине заготовок. Дальнейшие исследования проводились на кольцевых образцах, вырезанных из тела трубы. Исследована микроструктура околошовной зоны, проведены испытания на радиальное сжатие кольцевых образцов. Максимальная нагрузка составляла 10 тонн. В ходе осмотра зоны соединения биметалла расслоений обнаружено не было. Таким образом, режимы сварки взрывом позволили создать необходимые условия для очистки поверхности тугоплавкого сплава от оксидной пленки в процессе сварки и обеспечивают высокую прочность сцепления слоев без образования сплошных прослоек литого расплава.
\end{abstract}

Ключевые слова: Сварка взрывом, жаропрочный сплав, литейные дефекты, двухслойная трубная заготовка. 


\section{1. Введение}

Двухслойный металлический материал, который сочетает в себе высокую конструкционную прочность и способность к длительной работе в условиях воздействия на него высокоэнергетических конденсированных систем является перспективным для использования в различных отраслях промышленности, в том числе оборонной. В частности, при изготовлении стволов артиллерийских орудий разработчики сталкиваются со следующей проблемой - разработанные стали и сплавы не позволяют использовать новые (более мощные) метательные составы. При их использовании срок эксплуатации ствола, созданного по стандартным методикам из специальных оружейных сталей и сплавов, сокращается в разы. Поэтому, для того, чтобы получить возможность производить метание снаряда составами нового поколения, необходимо изготовлять стволы из материалов с повышенными эрозионностойкими свойствами (например, из биметаллов). В настоящей работе предлагается использовать энергию взрыва (сварка взрывом) для получения двухслойных трубных заготовок с внутренним слоем из жаропрочного никель-кобальтового сплава ЭК102 и наружным слоем из высокопрочной оружейной стали ОХНЗМ.

В связи с тем, что в составе сплава ЭК102 присутствуют такие тугоплавкие металлы, как вольфрам, кобальт, и хром соединение всеми видами сварки данного сплава с другими материалами затруднено. В некоторой степени это связано с наличием поверхностной тугоплавкой пленки $\left(\mathrm{Cr}_{2} \mathrm{O}_{3}, \mathrm{CoO}, \mathrm{NiO}\right)$ с температурой плавления более $2000 \mathrm{~K}$ [1]. Также необходимо отметить, что легирующие элементы связаны в сплаве в термически стабильные соединения, поэтому для активации поверхности в процессе сварки взрывом необходимо подобрать такие режимы, которые позволили бы разрушить межатомные связи в поверхностном слое [2]. Таким образом повысится активность и подвижность частиц кристаллической решетки, что будет способствовать схватыванию свариваемых поверхностей.

\section{2. Материалы и методика эксперимента}

Для проведения исследований в качестве исходных материалов использовались две трубы длиной 200 мм из сплава ЭК102 (32×2,5 мм) и стали ОХН3М ( $55 \times 9$ мм). Химический состав и механические свойства исходных материалов соответствуют ГОСТ5632-2014, ОСТ14-21-77 и представлены в таблицах 1 и 2.

Из данных, представленных в таблицах 1 и 2 видно, что свариваемые материалы имеют разный химический состав и физико-механические свойства. Это, в свою очередь, с большой долей вероятности может привести к появлению в околошовной зоне при сварке взрывом переходных сплавов с низкими прочностными свойствами (структур с повышенной твердостью и пониженной пластичностью) $[3,4]$. Также одним из факторов, затрудняющих качественное получение сваркой взрывом биметаллического изделия из исходных компонентов, является наличие тугоплавкой пленки на поверхности

Табл. 1. Химический состав исходных материалов.

Table 1. Chemical composition of materials.

\begin{tabular}{|c|c|c|c|c|c|c|c|c|c|}
\hline $\begin{array}{c}\text { Материал } \\
\text { Material }\end{array}$ & $\mathrm{Si}$ & $\mathrm{W}$ & $\mathrm{Mn}$ & $\mathrm{Ni}$ & $\mathrm{Co}$ & $\mathrm{Fe}$ & $\mathrm{Al}$ & $\mathrm{Cr}$ & $\mathrm{C}$ \\
\hline $\begin{array}{c}\text { ЭК102 } \\
\text { ЕК102 }\end{array}$ & $\leq 0,8$ & $13-16$ & $\leq 0,5$ & Осн. & $26-30$ & $\leq 3,0$ & $0,3-0,7$ & $20-23$ & $0,01-0,10$ \\
\hline $\begin{array}{c}\text { OХH3M } \\
\text { OHN3M }\end{array}$ & $0,17-0,37$ & - & $0,5-0,8$ & $2,75-3,75$ & - & Осн. & - & $0,7-1,1$ & $0,3-0,4$ \\
\hline
\end{tabular}

Табл. 2. Механические свойства исходных материалов.

Table 2. Mechanical properties of materials.

\begin{tabular}{|c|c|c|c|c|c|c|}
\hline Марка & $\begin{array}{c}\text { Темп. исп. } \\
T,{ }^{\circ} \mathrm{C}\end{array}$ & $\begin{array}{c}\text { Временное } \\
\text { сопротивление } \\
\text { разрыву, } \\
\sigma_{\sigma}, \text { МПа }\end{array}$ & $\begin{array}{c}\text { Предел } \\
\text { текучести, } \\
\sigma_{m}, \text { МПа }\end{array}$ & $\begin{array}{c}\text { Отн. удлинение } \\
\text { после разрыва, } \\
\delta, \%\end{array}$ & $\begin{array}{c}\text { Отн. сужение, } \\
\text { Ч, \% }\end{array}$ & $\begin{array}{c}\text { Ударная } \\
\text { вязкость, } \\
\mathrm{KCU}, \text { Дж/см² }\end{array}$ \\
\hline Mark & $\begin{array}{c}\text { Testing } \\
\text { temperature } \\
T,{ }^{\circ} \mathrm{C}\end{array}$ & $\begin{array}{c}\text { Tensile } \\
\text { strength } \\
\sigma_{\sigma}, \mathrm{MPa}\end{array}$ & $\begin{array}{c}\text { Yield } \\
\text { strength } \\
\sigma_{02}, \mathrm{MPa} \\
\end{array}$ & Aspect ratio $\delta, \%$ & $\begin{array}{c}\text { Contraction } \\
\text { ratio } \\
\Psi, \%\end{array}$ & $\begin{array}{l}\text { Impact } \\
\text { strength, } \\
\text { KCU, J/cm² }\end{array}$ \\
\hline \multirow{2}{*}{$\begin{array}{l}\text { ЭК102 } \\
\text { EK102 }\end{array}$} & 20 & $850-900$ & $300-380$ & $60-75$ & $60-65$ & $300-350$ \\
\hline & 1100 & $16-18$ & $100-120$ & $30-50$ & - & - \\
\hline $\begin{array}{l}\text { OXH3M } \\
\text { OHN3M }\end{array}$ & 20 & $950-1000$ & $800-810$ & $12-15$ & $40-45$ & $78-80$ \\
\hline
\end{tabular}


жаропрочного сплава, которая препятствует процессу самоочищения и активации поверхностей в процессе сварки взрывом [5,6].

Исходя из того, что свариваемые изделия имеют цилиндрическую форму, важным фактором, который необходимо учитывать при разработке технологии и расчетах параметров сварки взрывом, является максимальное сохранение цилиндричности двухслойной заготовки после взрывного воздействия.

Отталкиваясь от вышеперечисленных особенностей сварки взрывом цилиндрических изделий, была разработана поэтапная методика проведения исследований сварки взрывом исходных материалов:

- анализ физико-механических и химических свойств исходных компонентов;

- выбор оптимальной схемы сварки и расчет режимов, позволяющих получать качественное соединение разнородных материалов трубчатой формы с минимальным содержанием переходных структур на границе раздела;

- проведение опытного эксперимента по получению биметаллических трубных заготовок с сочетанием слоев «жаропрочный сплав ЭК102+ высокопрочная оружейная сталь ОХН3М»;

- ультразвуковой контроль сплошности соединения;

- изготовление контрольных кольцевых образцов из тела биметаллического образца;

- металлографический и рентгеноструктурный анализ зоны соединения в биметалле;

- проведение механических испытаний кольцевых образцов.

В качестве плакирующего слоя в данной работе применялся жаропрочный сплав на никель-кобальтовой основе ЭК102 (ВЖ145). Данный сплав является одним из самых распространенных материалов при производстве камер сгорания и дожигания, экранов, форсунок и высокотемпературных газоводов в авиационных газотурбинных двигателях [7]. Никель, хром и кобальт, входящие в состав данного сплава образуют основную фазу - матрицу сплава с гранецентрированной кубической решеткой $\gamma$-твердого раствора. В сплаве ЭК102 важна концентрация хрома для обеспечения высоких антикоррозионных свойств. Высокое сопротивление коррозии обусловливает коррозионностойкая пленка $\mathrm{Cr}_{2} \mathrm{O}_{3}$, образующаяся на поверхности сплава.

В качестве плакируемого материала выступала оружейная сталь ОХНЗМ. Данная сталь применяется для изготовления стволов артиллерийских систем [8].

Сварка взрывом исходных материалов осуществлялась по схеме с синхронным инициированием противозарядов (Рис. 1). Данная схема была выбрана как альтернатива схеме сварки цилиндрических изделий в матрице $[9,10]$.

Внутрь цилиндрической заготовки 5 из стали ОХНЗМ устанавливается труба 6 из сплава ЭК102. Для обеспечения требуемого зазора между заготовками и во избежание попадания в него взрывчатого вещества используется специальная крышка 7. Собранные таким образом трубы устанавливались на металлическую пла- стину 2, затем вся сборка помещалась на песчаную основу 1. Для уменьшения разлета взрывчатого вещества использовалась забойка из песка 3.

В качестве взрывчатого вещества использовался аммонит 6ЖВ с насыпной плотностью 1 г/ $\mathrm{cm}^{3}$.

\section{3. Результаты и их обсуждение}

В результате экспериментов были получены биметаллические образцы трубчатой формы без видимых повреждений внутреннего и наружного слоя. Дальнейшие исследования проводились на образцах, вырезанных из тела трубы (Рис. 2).

На Рис. 3 представлена микроструктура зоны соединения «ЭК102+ОХН3М» в продольном направлении.

Граница раздела в биметалле представляет собой линию с нерегулярным профилем. По всей длине соединения присутствуют локализованные участки с литыми включениями, имеющие усадочные пустоты. Данные участки появляются вследствие высокой пластической деформации и достижения в точке контакта высоких температур, достигающих температуры плавления исходных материалов. При этом стоит отметить, что данные области не перерастают в сплошную прослойку, а,

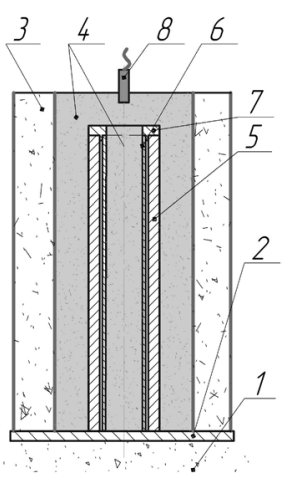

Pис. 1. Сборка для сварки взрывом: 1 - песчаная основа, 2 - металлическая пластина, 3 - забойка из песка, 4 - взрывчатое вещество, 5 - наружная труба из стали ОХН3М, 6 - внутренняя труба из никель-кобальтового сплава ЭК102, 7 - крышка, 8 - детонатор.

Fig. 1. Scheme of explosive welding: 1 - sand base, 2 - metal plate, 3 - sand, 4 - explosive, 5 - outer pipe of steel OHN3M, 6- inner pipe of alloy EK102, 7 - cap, 8 - detonator.

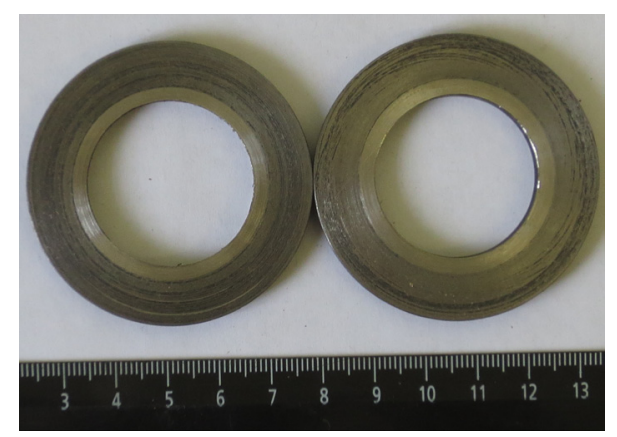

Рис. 2. Кольцевые биметаллические образцы (внутренний слой - ЭК102, наружный - ОХНЗМ).

Fig. 2. Circular bimetallic samples (inner layer - the EK 102, the outer - OHN3M). 
следовательно, имея небольшие линейные размеры, качественно не влияют на сцепление слоев в макромасштабе. Литые включения образовались в результате перемешивания элементов свариваемых материалов и быстрой кристаллизации расплава в замкнутом микрообъёме. Исходя из условий образования соединения при сварке взрывом (малые времена процесса и высокая скорость деформации), можно говорить о том, что структура в зоне сварки является метастабильной. В состав образовавшихся в результате сварки взрывом структур (Рис. 4) входят элементы исходных компонентов (таблица 3).

Для определения качества сцепления слоев, кольцевые образцы, вырезанные из биметаллической трубной заготовки, подвергались механическому испытанию на радиальное сжатие (Рис. 5). Максимальная нагрузка

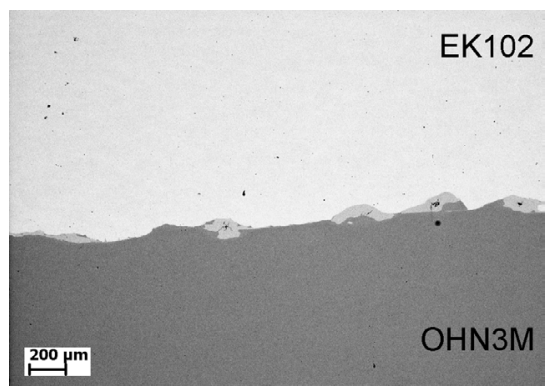

(a)

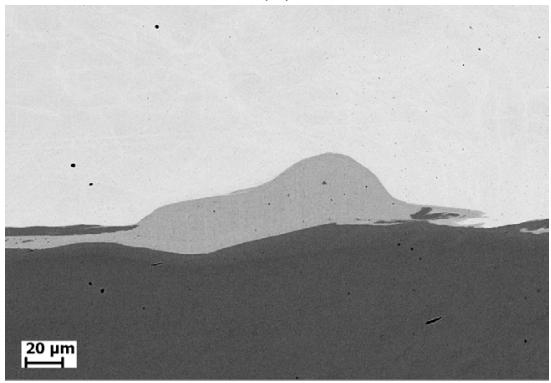

(b)

Рис. 3. Микроструктура зоны соединения ЭК $102+\mathrm{OXH} 3 \mathrm{M}$ (a) - общий вид границы раздела, (b) - участок с расплавом.

Fig. 3. The microstructure of the connection zone 102EK+OHN3M: general view of the interface (a), plot with the melt (b).

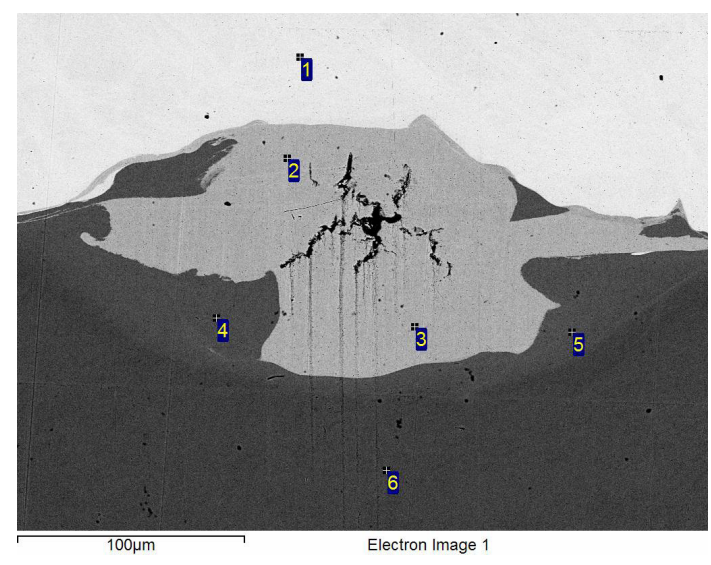

Рис. 4. Граница соединения биметалла ЭК $102+\mathrm{OXН3М}$ с участком литого включения.

Fig. 4. The connection zone EK102+OHN3M with a plot cast inclusion. составляла 10 тонн. В ходе осмотра зоны соединения биметалла расслоений обнаружено не было.

Исходя из полученных результатов исследований зоны соединения биметаллических трубных заготовок и механических испытаний можно сделать вывод, что сваркой взрывом можно получать качественные двухслойные изделия цилиндрической формы с сочетанием слоев «жаропрочный сплав ЭК102 и высокопрочная сталь ОХН3М». Режимы сварки взрывом позволяют создать необходимые условия для очистки поверхности тугоплавкого сплава от оксидной пленки в процессе сварки и обеспечивают высокую прочность сцепления слоев без сплошных прослоек литого расплава. Проведенный ультразвуковой контроль биметаллических образцов также показал, что соединение исходных материалов произошло на $100 \%$ уровне сплошности. На основании вышеизложенного можно говорить о перспективности расширения сферы применения вышеуказанных сплавов за счет их соединения в биметалле, вплоть до использования полученного материала для производства биметаллических стволов для артиллерийских систем (после соответствующих дополнительных исследований, в частности, на сопротивление термической или малоцикловой усталости).

Благодарность/Aknowledgements. Исследование выполнено при финансовой поддержке РФФИ в рамках научного проекта № 14-08-00845A.

Табл. 3. Химический состав переходных структур, масс. \% Table 3. Chemical composition of transitional structures, mass. \%

\begin{tabular}{|c|c|c|c|c|c|c|}
\hline № & $\mathrm{Al}$ & $\mathrm{Cr}$ & $\mathrm{Fe}$ & $\mathrm{Co}$ & $\mathrm{Ni}$ & $\mathrm{W}$ \\
\hline 1 & 1.28 & 21.88 & 0.98 & 26.75 & 34.52 & 14.60 \\
\hline 2 & 1.23 & 13.97 & 38.72 & 15.78 & 21.64 & 8.65 \\
\hline 3 & 0.97 & 14.26 & 37.82 & 16.21 & 21.58 & 9.17 \\
\hline 4 & 0.89 & 0.99 & 96.14 & - & 1.98 & - \\
\hline 5 & 0.90 & 1.03 & 95.86 & - & 2.21 & - \\
\hline 6 & 0.93 & 1.00 & 95.73 & - & 2.35 & - \\
\hline
\end{tabular}

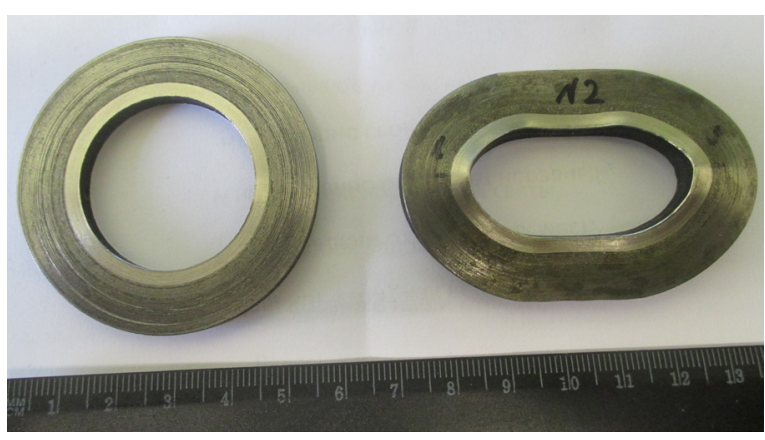

Рис. 5. Биметаллический кольцевой образец до и после механического испытания.

Fig. 5. The bimetallic circular sample before and after the mechanical tests. 


\section{Литература/References}

1. G. Samsonov. Physico-chemical properties of oxides. Moscow. Metallurgy. (1978) 472 p. (in Russian) [Г.В. Самсонов. Физико-химические свойства окислов. Москва, Металлургия. 1978. 472 с.]

2. K. Kochergin. Pressure welding. Textbook. Leningrad. Mashinostroenie. (1972) 216 p. (in Russian) [К.А. Кочергин. Сварка давлением. Ленинград, Машиностроение. 1972. 216 с.]

3. Y. Konon, L. Pervukhin, A. Chudnovsky. Explosive welding. Textbook. Moscow. Mashinostroenie. (1987) 216 p. (in Russian) [Ю. А Конон., Л.Б. Первухин, А.Д. Чудновский. Сварка взрывом. Москва, Машиностроение. 1987.216 с.]

4. K. Charukhina, S. Golovanenko, V. Masterov, N. Kozakov. The bimetallic connection. Textbook. Moscow. Metallurgy. (1970), 280 p. (in Russian) [К.Е. Чарухина, С.А. Голованенко, В.А. Мастеров, Н.Ф. Казаков. Биметаллические соединения. Москва, Металлургия. 1970. 280 c.]

5. A. Berdychenko, M. Flat. Polzunovskii almanah. 1, 210
(2010) (in Russian) [А.А. Бердыченко, М.Х. Флат. Ползуновский альманах. 1, 210 (2010)]

6. S. Solov'ev, G. Korablev. Bulletin of ISTU them. M. T. Kalashnikov. 1, 34 (2006) (in Russian) [С.Д. Соловьев, Г.А. Кораблев. Вестник ИжГТУ им. М. Т. Калашникова. 1, 34 (2006)]

7. B. Lomberg, S. Moiseev. All of the materials. Encyclopedic reference. 6, 2 (2007) (in Russian) [Б.С. Ломберг, С.А. Моисеев. Все материалы. Энциклопедический справочник. 6, 2 (2007)]

8. G. Tuktanov. Technology production of small-gun and artillery weapons: a textbook for university students. Moscow. Mashinostroenie. (2007) 375 p. (in Russian) [А.Г. Туктанов. Технология производства стрелково-пушечного и артиллерийского оружия: учебник для студентов вузов. Москва. Машиностроение. 2007. 375 c.]

9. Wei Deng, Ming Lu, Xiaojie Tian, Rxun Dai. Advanced in Mechanical Engineering and its Applications (AMEA). 2, 304 (2013)

10. Ehsan Zamani, Gholam Hossien Liaghat. Journal Mater Sci. 47. 685 (2012) 